\title{
Assessing the Ecological Sensitivity of Coastal Marine Ecosystems: A Case Study in Xiamen Bay, China
}

\author{
Wenjia Hu ${ }^{1,2}$, Weiwei Yu ${ }^{1,2}$, Zhiyuan Ma ${ }^{1,2}$, Guanqiong Ye ${ }^{3}$, Ersha Dang ${ }^{1}$, Hao Huang ${ }^{1,2}$, \\ Dian Zhang ${ }^{1}$ and Bin Chen ${ }^{1,2, *}$ \\ 1 Third Institute of Oceanography, Ministry of Natural Resources, Xiamen 361005, \\ China; huwenjia@tio.org.cn (W.H.); yuweiwei@tio.org.cn (W.Y.); mazhiyuan@tio.org.cn (Z.M.); \\ ershadang@outlook.com (E.D.); huanghao@tio.org.cn (H.H.); zhangdian@tio.org.cn (D.Z.) \\ 2 Fujian Provincial Key Laboratory of Marine Ecological Conservation and Restoration, Xiamen 361005, China \\ 3 Ocean College, Zhejiang University, Zhoushan 316021, China; gqy@zju.edu.cn \\ * Correspondence: chenbin@tio.org.cn
}

Received: 9 September 2019; Accepted: 11 November 2019; Published: 13 November 2019

check for updates

\begin{abstract}
Coastal marine ecosystems are sensitive to anthropogenic stressors and environmental change. The Chinese Government proposed an ecosystem-based marine spatial planning scheme called the "Marine Ecological Red Line" (MERL), aimed at protecting ecologically sensitive areas. The assessment and mapping of ecosystem sensitivity provide important tools for regional MERL and setting conservation priorities. In this study, an integrated framework for the comprehensive sensitivity assessment of coastal marine ecosystems was proposed. This framework had two components: endogenous sensitivity and exogenous sensitivity. A weighted summation method was used along with a GIS-based spatial analysis to calculate regional sensitivity quantitatively. Taking Xiamen Bay in China as a case study, the approach integrated spatial data on the distribution of marine habitats and multiple human activities. An index system (including 26 indicators) was established for the case study. Five areas with different levels of sensitivity were delineated. In the study region of $1281 \mathrm{~km}^{2}$, areas with extremely high and high sensitivity covered $87 \mathrm{~km}^{2}$ and $235 \mathrm{~km}^{2}$, respectively, and were hypothesized to be priority areas of conservation and regulation. Areas with the highest sensitivity were located closer to Jiulongjiang Estuary and along the coastline of Xiang'an. Areas with lower sensitivity were also mapped in Tong'an Bay, representing possible areas that could accommodate future industrial or intensive human use. Comparative analyses between endogenous sensitivity and exogenous sensitivity allowed the presence of development-protection conflict zones to be identified. The results provide an important scientific basis for MERL decisions. In addition, targeted management strategies were proposed for Xiamen Bay. This study presents an operational approach to provide relevant scientific knowledge on the process of ecosystem-based marine spatial planning, facilitating policy-making decisions in sustainable coastal and marine management.
\end{abstract}

Keywords: ecologically sensitive areas; marine ecosystem assessment; ecosystem-based marine spatial planning

\section{Introduction}

Coastal marine ecosystems provide a variety of ecosystem services for humans; however, these systems are susceptible to both terrestrial and marine factors because they are situated in the coastal ecotone $[1,2]$. Consequently, coastal marine ecosystems are very sensitive to environmental change and human activities [3-5]. Marine ecosystem services are declining due to various problems, including marine pollution, eutrophication, habitat loss, and the degradation of biodiversity [6-11]. However, ocean uses 
are still often located in sensitive biological and ecological areas without much consideration of their impact [12].

To achieve coordinated development of the population, economy, and environment in the coastal area, the Chinese Government proposed a new round of marine spatial planning (MSP) schemes in 2015 called the "Marine Ecological Red Line" (MERL) [13-15]. The new MERL aims to protect ecologically sensitive areas and important ecological functions and to develop reasonable boundaries for development and industrial layout. Although the "Redline" policies have been proposed for several years, technical components of the MERL approach have remained limited [16]. Insufficient ecological information and inappropriate zoning are the main challenges during the MSP and management process.

In the MERL, areas with high ecological sensitivity must include and will be regulated by strict criteria. Ecological sensitivity refers to the degree of reflection of ecosystem interference in human activities and changes to the natural environment; that is, the degree to which the ecosystem responds to environmental changes caused by the combination of internal and external factors [17]. In the long term, higher ecological sensitivity results in a greater likelihood of species loss and exacerbation of ecological diversity [18]. Through identifying highly sensitive areas, conservation and management strategies could be developed that facilitate the sustainable use of coastal resources [19-21].

Existing studies on marine ecosystem sensitivity assessments usually focus on the sensitivity of a particular species or group of species (e.g., benthos, fishes) to certain factors, including eutrophication [22,23], fishing [24], climate change [25], heavy metal pollution [26], and recreational activities [27]. However, due to the complexity of coastal marine ecosystems, research on the integrated assessment of marine ecosystem sensitivity remains limited. In coastal marine ecosystems, sensitive areas are subjected to a varied catalog of anthropogenic actions. It is often too difficult to evaluate all of the inter-related elements comprehensively because of their diffuse nature [28].

To assess such complex systems, ecological factors and human activities are often assessed using social-ecological integrated approaches [29]. Commonly used frameworks include the DPSIR framework, the ecosystem services framework, and the IEA framework [30-33]. Under these frameworks, various evaluation methods are used in sensitivity assessments, including the social-ecological GIS model, the AHP method, fuzzy sets, and landscape ecology assessments [28,34-36]. The ecological sensitivity of lagoons, islands, tidal flats, and bays has been evaluated using these methods by providing a scientific basis for planning and management [28,34-37]. However, few studies have mapped the sensitivity of a complex coastal sea region supporting multiple ecosystem types.

Therefore, this study proposed an integrated assessment approach to evaluate the ecological sensitivity of a coastal marine area. Through integrating comprehensive spatial information, the assessment and mapping of ecological sensitivity was used to identify key ecological features for setting conservation priorities, as well as sources that might negatively impact regional marine ecosystems [38-45]. Taking Xiamen Bay in China as an example, a set of indicators was proposed to evaluate regional sensitivity quantitatively. Xiamen Bay is located on the southeast coast of China. As one of 44 key bays in China, Xiamen Bay is surrounded by the cities of Xiamen, Quanzhou, and Zhangzhou, which contain more than 5 million people, making it the most developed area in Fujian Province. Since the last planning period ends in 2020, the local governments have recently implemented the new planning of MERL. To meet the ecological goals, the ecologically sensitive areas in Xiamen Bay must be identified and regulated under the new MSP. First, this study aimed to establish a complex assessment framework of ecological sensitivity for the coastal sea area, including biological, ecological and utilization factors. Secondly, by mapping sensitivity, this study aimed to select the priority sites for regulation in the MERL. The results were applied to establish the relevance of spatial patterns in sensitivity and to suggest how to implement the governance strategy aimed at sustainable conservation and utilization to provide highly effective support for local MSP. 


\section{Materials and Methods}

\subsection{Study Area}

Xiamen Bay is located on the southeastern coast of Fujian Province, China $\left(117.48^{\prime} 55.18^{\prime \prime}-117.34^{\prime} 46.77^{\prime \prime}\right.$ $\mathrm{E}$ and $24.14^{\prime} 33.23^{\prime \prime}-24.42^{\prime} 23.70^{\prime \prime} \mathrm{N}$ ) and has a total marine area of $1281 \mathrm{~km}^{2}$ (Figure 1). The bay contains many habitat types (including mangrove wetlands and sandy beaches) and diverse biological groups (including two flagship species, the Chinese white dolphin Sousa chinensis and amphioxus Branchiostoma balcheri) [46,47]. Xiamen Bay is also affected by intensive development activities, including shipping, aquaculture, reclamation, and tourism. These activities have led to a number of issues, including a decline in marine biodiversity, habitat loss, and water pollution [48]. To achieve sustainable development, local governments have been attaching importance to ecosystem-based management for many years $[49,50]$. Therefore, Xiamen Bay is representative of ecological sensitivity assessments, with the current study providing key scientific support to local MSP goals.

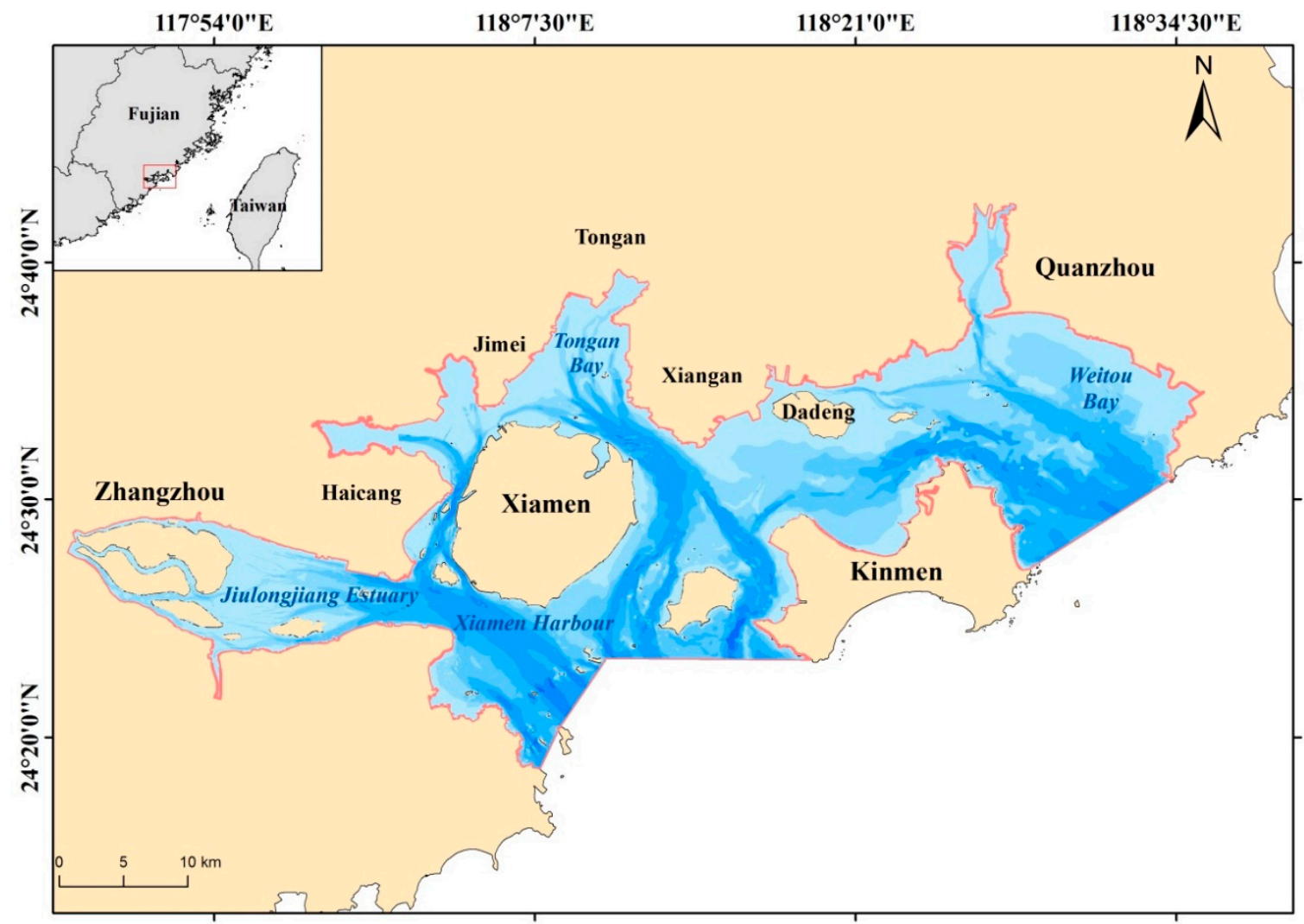

Figure 1. Study area of Xiamen Bay, China.

\subsection{Ecological Sensitivity Assessment Framework and Indicators}

In light of MERL, marine ecosystem sensitivity in this study interprets the possibility and extent of ecological environmental problems caused by external disturbances. Higher sensitivity suggests a higher possibility of ecological problems. Therefore, the marine ecosystem sensitivity assessment framework developed here contained two important components: endogenous sensitivity and exogenous sensitivity (Figure 2). 


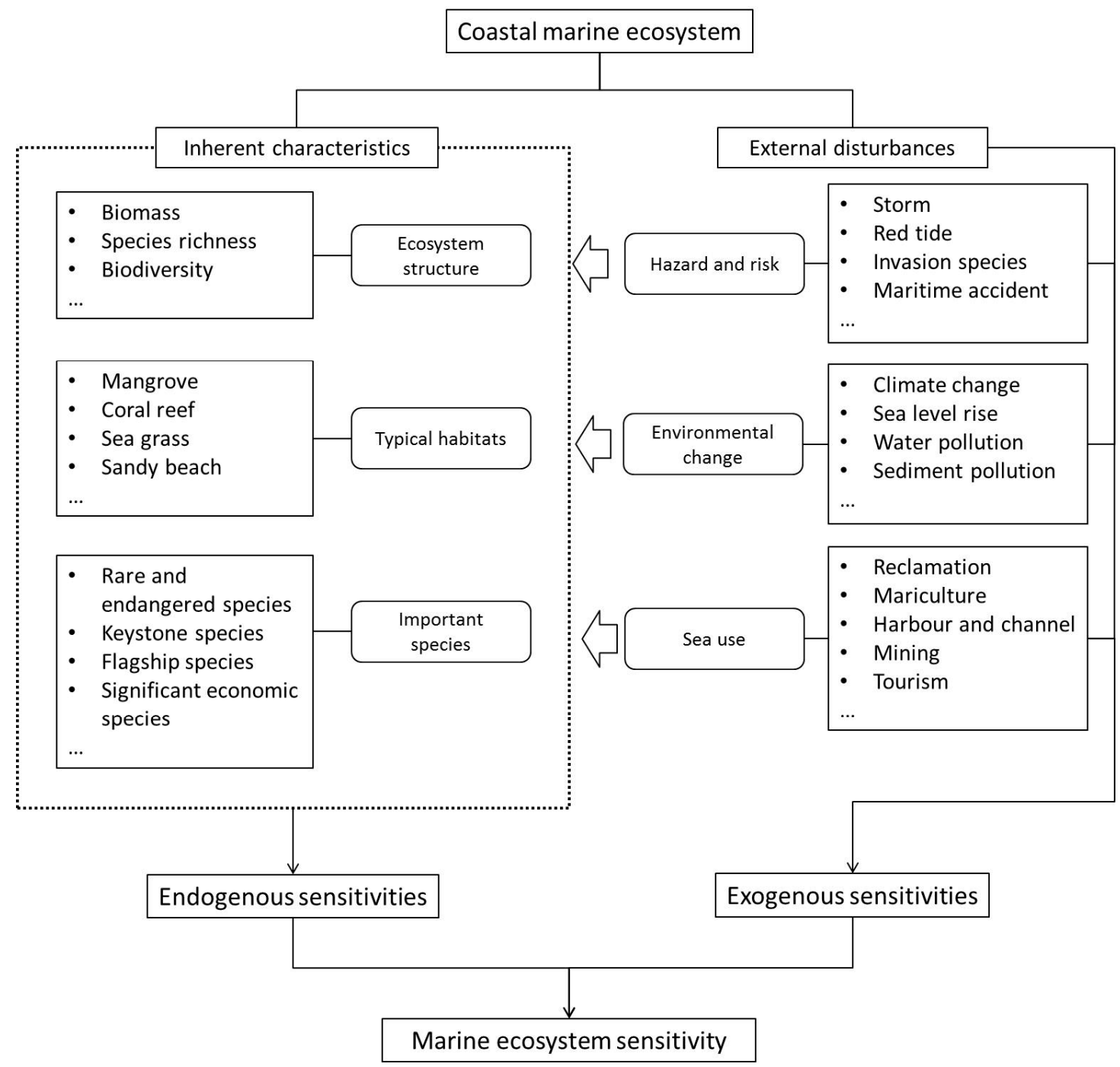

Figure 2. Framework of marine ecosystem sensitivity assessment.

Endogenous sensitivity refers to sensitivity characteristics that are inherent within a given ecosystem. When the endogenous sensitivity of an area is high, environmental problems might cause the loss of typical habitats and regional biodiversity. Endogenous sensitivity is mainly reflected by certain features of marine ecosystems, including the distribution of sensitive habitats and species with high conservation value, and the structural characteristics of a given ecosystem. The former is assessed using typical habitats (such as mangroves, coral reefs, and sea grass systems), significant areas in the life-history of important species (such as spawning grounds, feeding grounds, migration channels), and/or areas with concentrated distributions of rare and endangered species. The latter is evaluated by the richness, biomass, or diversity index of phytoplankton, zooplankton, nektons, and benthic organisms.

Exogenous sensitivity refers to external disturbances to the natural ecosystem, i.e., pressures on ecosystems and species. Exogenous sensitivity includes disturbance that is not directly associated with human activities (such as climate change, risk events, and changes to water and sediment quality), and the direct use of oceans by humans (such as mariculture, reclamation, fishing, and tourism).

Endogenous and exogenous sensitivity were combined to determine the integrated sensitivity of the study region. Higher endogenous sensitivity suggests that a region or a certain object is more susceptible to pressure. In comparison, higher exogenous sensitivity suggests that a region is being subject to stronger disturbance from natural or human factors. From the perspective of 
management (Figure 3), regions that are high in both endogenous and exogenous sensitivity are more likely to be subject to conflicts between conservation and development. Therefore, such areas are hypothesized to be priority areas for regulation in the MSP. For example, in these areas, detailed zoning management or setting exit mechanisms for conflicting development may be implemented beforehand. Regions with large differences between endogenous and exogenous sensitivity are less likely to develop problems. Furthermore, regions that have low endogenous and exogenous sensitivity could be used to accommodate development spillover from other regions and share their development burden.

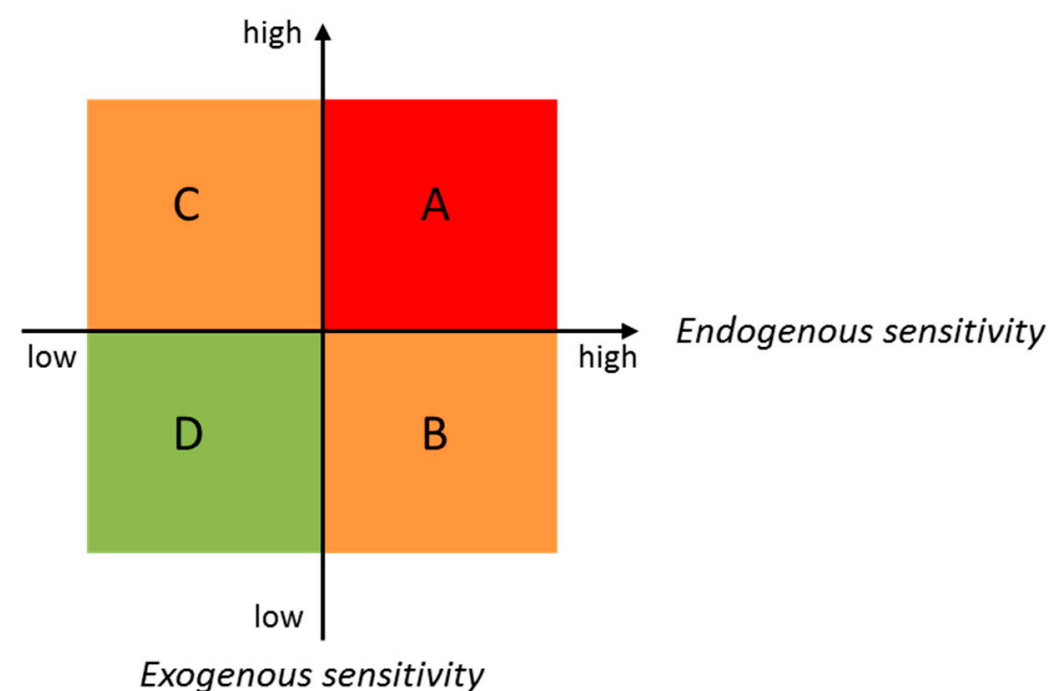

Section A: high endogenous sensitivity + high exogenous sensitivity = Problems exist, priority area for management Section B: high endogenous sensitivity + low exogenous sensitivity $=$ Good, maintain the status Section C: low endogenous sensitivity + high exogenous sensitivity = Good, regulate the disturbance Section D: low endogenous sensitivity + low exogenous sensitivity = Potential area for future development

Figure 3. Combinations of exogenous and endogenous ecological sensitivity and management strategies.

In the application process, different indicators from different components of this framework could be proposed according to the social-ecological characteristics of certain study areas. Specific indicators might vary depending on ecosystem type, ecological characteristics, and the scale of the study area. In this study, an index system was developed for Xiamen Bay under the framework of the ecological sensitivity analysis. Twenty-six indicators across four different levels were used based on the natural geographical characteristics of the region and the availability of data (Table 1). 
Table 1. Ecosystem sensitivity assessment indicators of Xiamen Bay.

\begin{tabular}{|c|c|c|c|c|}
\hline Target Level & Criterion Level & Factor Level & Indicator level & Source of Data \\
\hline \multirow{15}{*}{$\begin{array}{l}\text { Ecosystem sensitivity of Xiamen } \\
\text { Bay A1 }\end{array}$} & \multirow{10}{*}{$\begin{array}{l}\text { Endogenous sensitivity } \\
\text { B1 }\end{array}$} & \multirow{5}{*}{$\begin{array}{l}\text { Distribution areas of typical } \\
\text { habitats and important species } \\
\text { C1 }\end{array}$} & Mangrove D1 & $\begin{array}{l}\text { Interpretation of satellite remote } \\
\text { sensing images of } 2014\end{array}$ \\
\hline & & & Waterfowl habitat D2 & $\begin{array}{l}\text { Field survey in the winters of } \\
\text { 2013-2014 }\end{array}$ \\
\hline & & & $\begin{array}{l}\text { Chinese White Dolphin habitat } \\
\text { D3 }\end{array}$ & $\begin{array}{l}\text { Field survey in December of } \\
2010-2014\end{array}$ \\
\hline & & & Amphioxus habitat D4 & Field survey in September 2015 \\
\hline & & & Sandy beach D5 & $\begin{array}{l}\text { Interpretation of satellite remote } \\
\text { sensing images of } 2014\end{array}$ \\
\hline & & & Chlorophyll $a$ content D6 & Field survey from 2012 to 2015 \\
\hline & & & $\begin{array}{l}\text { Biodiversity index of } \\
\text { phytoplankton D7 }\end{array}$ & Field survey from 2012 to 2015 \\
\hline & & Marine biome $\mathrm{C} 2$ & $\begin{array}{l}\text { Biodiversity index of } \\
\text { zooplankton D8 }\end{array}$ & Field survey from 2012 to 2015 \\
\hline & & & $\begin{array}{l}\text { Biodiversity index of benthos } \\
\text { D9 }\end{array}$ & Field survey from 2012 to 2015 \\
\hline & & & $\begin{array}{l}\text { Biodiversity index of nekton } \\
\text { D10 }\end{array}$ & Field survey from 2012 to 2015 \\
\hline & \multirow{5}{*}{$\begin{array}{l}\text { Exogenous sensitivity } \\
\text { B2 }\end{array}$} & \multirow[t]{2}{*}{ Hazard and risk $\mathrm{C} 3$} & $\begin{array}{l}\text { Annual frequency of red tide } \\
\text { D11 }\end{array}$ & $\begin{array}{l}\text { The Xiamen Marine } \\
\text { Environment Bulletin reports of } \\
\text { 2005-2014 }\end{array}$ \\
\hline & & & Invasive species D12 & $\begin{array}{l}\text { Interpretation of satellite remote } \\
\text { sensing images of } 2014\end{array}$ \\
\hline & & \multirow{3}{*}{ Sea-use activities $C 4$} & Mariculture D13 & $\begin{array}{l}\text { Interpretation of satellite remote } \\
\text { sensing images of } 2014\end{array}$ \\
\hline & & & Reclamation D14 & $\begin{array}{l}\text { Interpretation of satellite remote } \\
\text { sensing images of 2014, and } \\
\text { Fujian Marine Functional } \\
\text { Zoning (2011-2020) }\end{array}$ \\
\hline & & & Channel and harbor D15 & $\begin{array}{l}\text { Fujian Marine Functional } \\
\text { Zoning (2011-2020) }\end{array}$ \\
\hline
\end{tabular}


Table 1. Cont.

\begin{tabular}{|c|c|c|c|c|}
\hline Target Level & Criterion Level & Factor Level & Indicator level & Source of Data \\
\hline & & \multirow{11}{*}{ Environmental quality C5 } & Petroleum in water D16 & $\begin{array}{l}\text { The trend monitoring report on } \\
\text { marine environment in coastal waters } \\
\text { of Xiamen in } 2016\end{array}$ \\
\hline & & & Organic pollution in water D17 & $\begin{array}{l}\text { The trend monitoring report on } \\
\text { marine environment in coastal waters } \\
\text { of Xiamen in } 2016\end{array}$ \\
\hline & & & Inorganic nitrogen in water D18 & $\begin{array}{l}\text { The trend monitoring report on } \\
\text { marine environment in coastal waters } \\
\text { of Xiamen in } 2016\end{array}$ \\
\hline & & & Active phosphate in water D19 & $\begin{array}{l}\text { The trend monitoring report on } \\
\text { marine environment in coastal waters } \\
\text { of Xiamen in } 2016\end{array}$ \\
\hline & & & Organic carbon in sediment D20 & $\begin{array}{l}\text { The trend monitoring report on } \\
\text { marine environment in coastal waters } \\
\text { of Xiamen in } 2016\end{array}$ \\
\hline & & & Sulfides in sediment D21 & $\begin{array}{l}\text { The trend monitoring report on } \\
\text { marine environment in coastal waters } \\
\text { of Xiamen in } 2016\end{array}$ \\
\hline & & & $\begin{array}{l}\text { Polychlorinated biphenyls in } \\
\text { sediment D22 }\end{array}$ & $\begin{array}{l}\text { The trend monitoring report on } \\
\text { marine environment in coastal waters } \\
\text { of Xiamen in } 2016\end{array}$ \\
\hline & & & Heavy metals in sediment D23 & $\begin{array}{l}\text { The trend monitoring report on } \\
\text { marine environment in coastal waters } \\
\text { of Xiamen in } 2016\end{array}$ \\
\hline & & & Petroleum in sediment D24 & $\begin{array}{l}\text { The trend monitoring report on } \\
\text { marine environment in coastal waters } \\
\text { of Xiamen in } 2016\end{array}$ \\
\hline & & & Heavy metals in organisms D25 & $\begin{array}{l}\text { The Xiamen Marine Environment } \\
\text { Bulletin reports of 2014-2015 }\end{array}$ \\
\hline & & & Petroleum in organisms D26 & $\begin{array}{l}\text { The Xiamen Marine Environment } \\
\text { Bulletin reports of 2014-2015 }\end{array}$ \\
\hline
\end{tabular}




\subsection{Data Processing}

Given that the identified indicators were expressed as different units and measured in different ways, it was not possible to perform a direct calculation on them in the spatial analysis process. Thus, standardized approaches incorporated in GIS-based spatial analysis were proposed here to overcome this problem. A two-step general process was developed to process the original data for subsequent calculation.

\section{Standardization of indicators}

Two methods were used to standardize the indicators to a range of $0-1$. We classified all of the indicators into two types based on their characteristics. Indicator type I mainly used field survey data, with one value for each survey site (e.g., environmental quality). Indicator type II represented the distribution range of certain objects or activities, which were presented as presence or absence (e.g., typical habitats, channels, and harbors).

A quantitative method was used for indicators acquired by field measurements at certain sites (Indicator Type I). Of these, the positive indicators are standardized by Equation (1):

$$
Z_{i}=\frac{X_{i}-\min \left(X_{i}\right)}{\max \left(X_{i}\right)-\min \left(X_{i}\right)}
$$

while all negative indicators are standardized by Equation (2):

$$
Z_{i}=\frac{\max \left(X_{i}\right)-X_{i}}{\max \left(X_{i}\right)-\min X_{i}}
$$

where $Z_{i}$ is the standardized value of indicator $i ; X_{i}$ is the original value of indicator $i$; $\max \left(X_{i}\right)$ is the maximum value of indicator $i$ within the study period; $\min \left(X_{i}\right)$ is the minimum value of index $i$ within the study period.

A qualitative scoring method was adopted for indicators that did not have measurement values (Indicator Type II). These indicators were characterized by their distribution status. A value of 1 was set for presence and 0 was set for absence.

\section{Generating the indicator layers}

The research region was separated into $50 \mathrm{~m} \times 50 \mathrm{~m}$ grids. Then, different spatial analysis methods were adopted to generate sensitivity indicator layers. According to the varied traits of different indicators, three interpolation/analysis methods were used in this study (Table 2).

\begin{tabular}{|c|c|c|c|}
\hline & & $\begin{array}{l}\text { Standardization } \\
\text { Method }\end{array}$ & $\begin{array}{l}\text { Spatial Analysis } \\
\text { Method }\end{array}$ \\
\hline \multirow[t]{2}{*}{ Type I } & $\mathrm{C} 2, \mathrm{C} 5$ & Quantitative method & $\begin{array}{l}\text { Kriging interpolation } \\
\text { method }\end{array}$ \\
\hline & C1(D3 and D4) & Quantitative method & Kernel density analyst \\
\hline \multirow{2}{*}{ Type II } & C1(D1, D2 and D5) & $\begin{array}{l}\text { Qualitative scoring } \\
\text { method }\end{array}$ & 0/1 (absence/presence) \\
\hline & $\mathrm{C} 3, \mathrm{C} 4$ & $\begin{array}{l}\text { Qualitative scoring } \\
\text { method }\end{array}$ & $\begin{array}{l}\text { Inverse distance } \\
\text { weighted method }\end{array}$ \\
\hline
\end{tabular}

Table 2. Data processing methods for different indicators.

For type I indicators, the Kriging interpolation method and Kernel density analysis were implemented to generate layers for each indicator. For type II indicators, two situations existed. For indicators describing the distribution of biomes or ecosystems, the scoring values of 0 or 1 were directly set to every grid. However, sensitivity indicators related to human activities (such as reclamation, channels, and mariculture) were considered differently, as their values were spatially 
dependent, i.e., their impacts decreased with increasing distance. Therefore, the inverse distance weighted method was chosen. All of the spatial interpolation/analysis processes were conducted using the Spatial Analyst tools in ArcGIS 10.2 software. The map layers were generated using the same software.

\subsection{Calculation of Comprehensive Sensitivity}

In the comprehensive evaluation process of multiple indicators, different indicators contributed differently to sensitivity. Thus, the appropriate weighting had to be allocated to each indicator. In the case of Xiamen Bay, weight was determined using the Delphi method and the analytical hierarchy process [51-53]. A weighting questionnaire was designed and 12 experts were invited to score the weight between 0 and 1 . After multiple rounds of inquiries, the weighting of the metrics was finally decided (see weighting chart in Appendix A). Then, multi-factor weighted summation was performed on the indicators according to Equation (3):

$$
S=\sum_{i=1}^{n} W_{i} Z_{i}
$$

where $S$ denotes the comprehensive sensitivity index, $Z_{i}$ denotes the standardization value of indicator $i, W_{i}$ denotes the weight of the indicator $i$, and $n$ denotes the number of indicators used in the sensitivity assessment.

A comprehensive sensitivity score was calculated for each grid. In similar existing studies, the sensitivity values tended to be divided into four or five levels using the equal interval method or natural breakpoint method [54]. In this study, we divided the sensitivity index into five levels: "extremely low", "low", "medium", "high", and "extremely high". The natural breakpoint method was chosen for the classification because it provided the best representation of the original data characteristics of each sensitivity level in this case study (Figure 4).

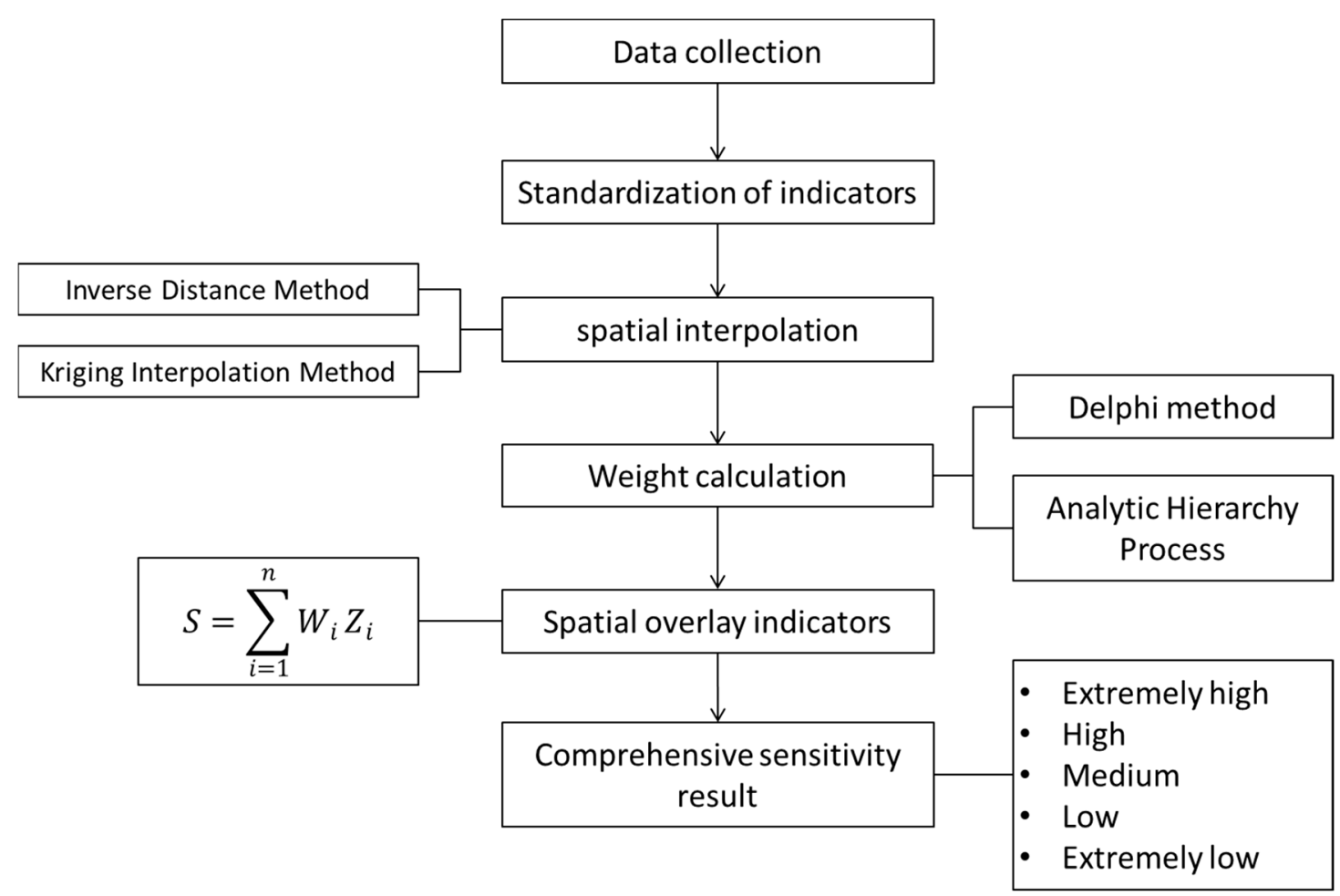

Figure 4. Steps used in the sensitivity assessment. 


\section{Results}

\subsection{Endogenous Sensitivity}

According to the assessment framework of marine ecological sensitivity, areas with high endogenous sensitivity indicate high ecological significance. Areas identified as having high endogenous sensitivity in Xiamen Bay were consistent with the observed situation (Figure 5). These areas were mainly distributed in parts of Jiulongjiang Estuary, the southeastern coast of Xiamen Island, and around Dadeng Island. The main habitats of the mangrove wetlands, dolphins, and amphioxus were located in these areas, part of which overlapped with local MPAs.

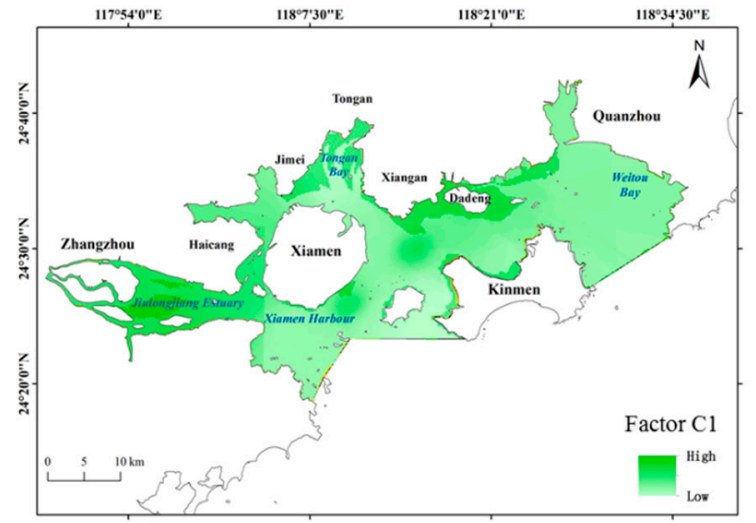

(a)

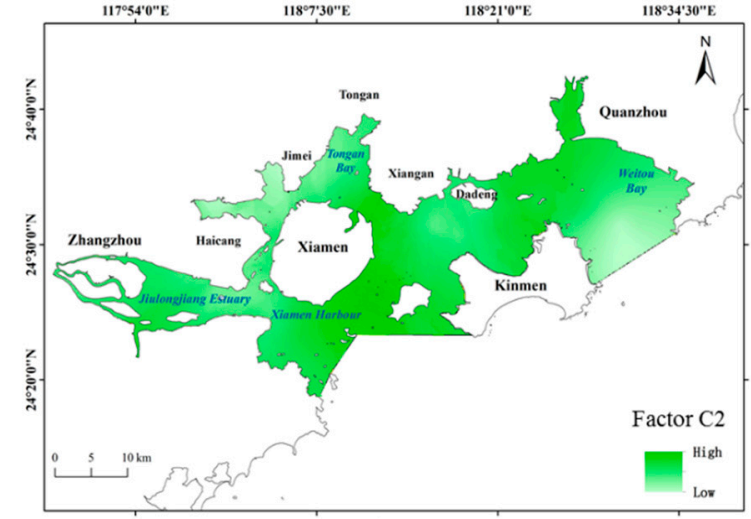

(b)

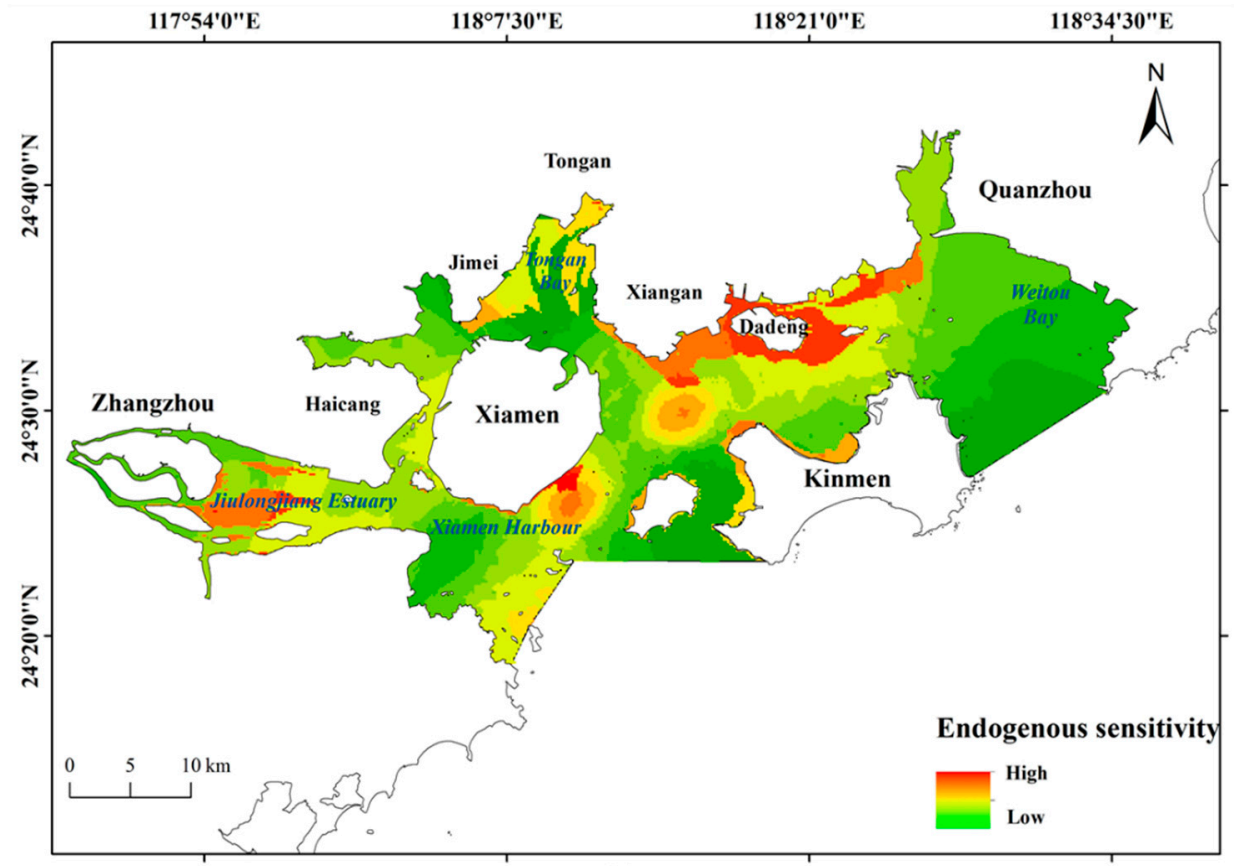

(c)

Figure 5. Layers of endogenous sensitivity in Xiamen Bay. (a) layer of endogenous sensitivity factor C1; (b) layer of endogenous sensitivity factor C2; (c) spatial pattern of endogenous sensitivity in Xiamen Bay).

For typical ecosystems and important species, sensitivity related to their habitats was mapped in the layer of factor C1 (Figure 5a). The sea area surrounding Dadeng Island supports important habitat for waterfowl. The Chinese White Dolphin is distributed in the western and eastern areas of the bay. Amphioxus inhabits the sandy habitats along the southeastern coast of Xiamen Island. 
It is recognized as a representative species in the history of biological evolution, and is very sensitive to water quality. Pristine sandy beaches exist along the coasts of Kinmen Island and the southern part of Xiamen Island. In Jiulongjiang Estuary, an MPA was established for the mangrove wetland. Over the last three decades, local mangroves have become seriously degraded; however, a pristine natural mangrove forest is maintained in the MPA. In addition, the distribution of biomes that contain plankton, nekton, and benthos were mapped in the layer of factor C2. These biomes were concentrated in Jiulong River Estuary, east of Xiamen Island, and north of Kinmen Island (Figure 5b).

\subsection{Exogenous Sensitivity}

As an index of potential disturbance, exogenous sensitivity tended to be higher in the southwestern part of Xiamen Bay and lower in the eastern part (Figure 6). The Jiulongjiang River is the main river flowing into Xiamen Bay and is subject to intensive human activities and high-intensity development. In all of the layers of factors C3, C4, and C5, high exogenous sensitivity was observed in and around Jiulongjiang Estuary (Figure 7).

The west and southwest side of Xiamen Island is the main channel of Xiamen Harbor, which ranked 14th in the world's harbors in terms of container throughput in 2017. Sensitivity indicators of sea-use activities and environmental quality were relatively higher in these areas (Figure $7 \mathrm{~b}, \mathrm{c}$ ). Areas with high exogenous sensitivity also existed along the coast of Haicang, Xiang'an, and Quanzhou, due to long-standing reclamation activities (Figure $7 \mathrm{~b}$ ). Since 1950, a total of 62 coastal reclamation projects have been conducted on the marine areas of Xiamen, covering 125.74 ha. These reclamation projects have changed the hydrological and sedimentary conditions of the marine habitats in Xiamen Bay, leading to habitat loss and a decline in biodiversity.

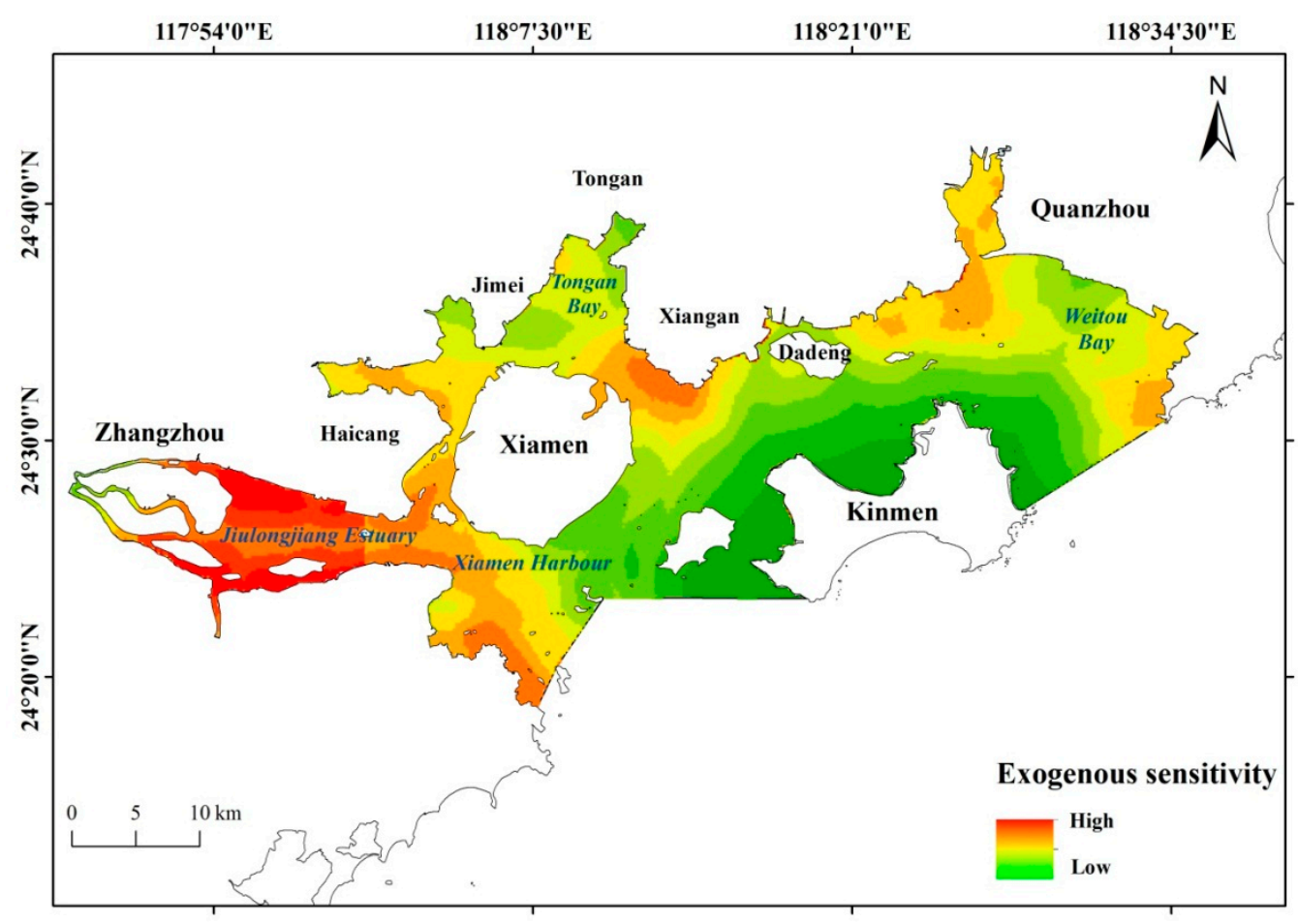

Figure 6. Spatial pattern of exogenous sensitivity in Xiamen Bay. 


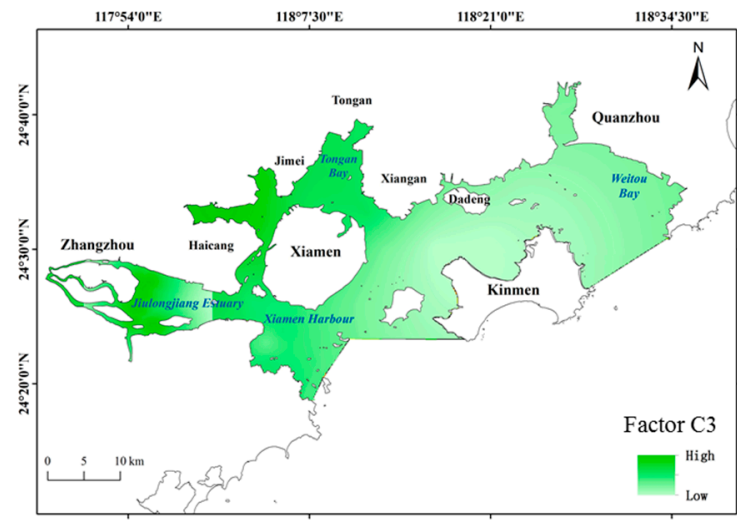

(a)

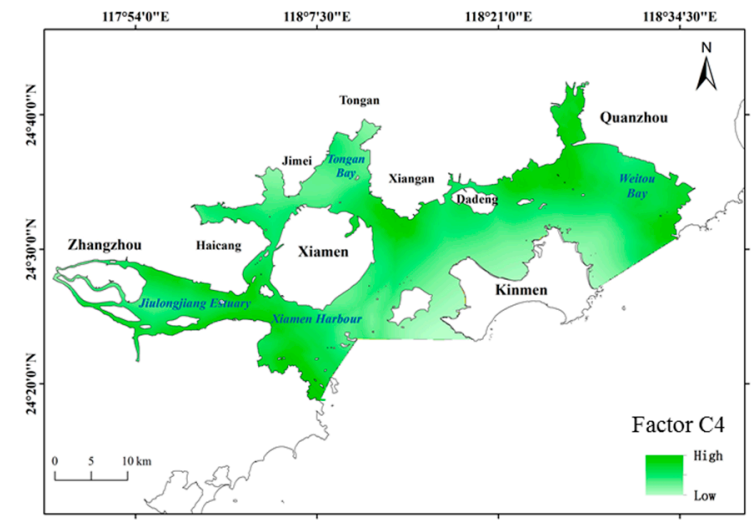

(b)

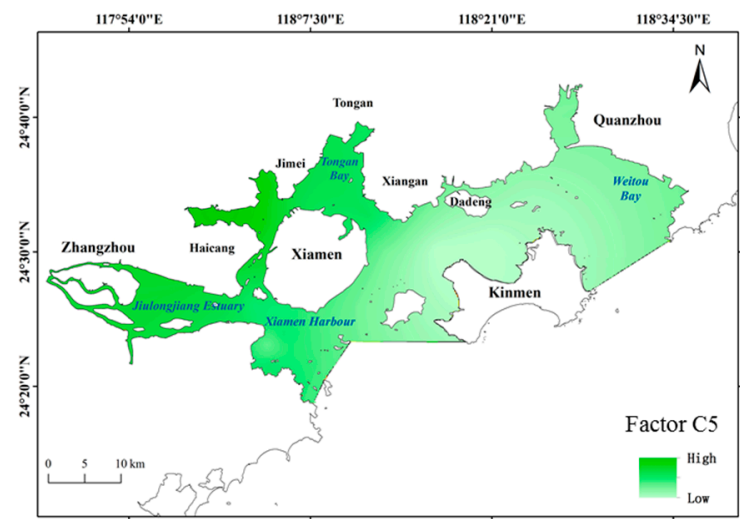

(c)

Figure 7. Layers of exogenous sensitivity in Xiamen Bay. (a) layer of exogenous sensitivity factor C3; (b) layer of exogenous sensitivity factor C4; (c) layer of exogenous sensitivity factor C5).

\subsection{Ecological Sensitivity Distribution in Xiamen Bay}

The results of our calculation show that Xiamen Bay contains $143 \mathrm{~km}^{2}$ of extremely low sensitive areas, $298 \mathrm{~km}^{2}$ of low sensitive areas, $395 \mathrm{~km}^{2}$ of medium sensitive areas, $235 \mathrm{~km}^{2}$ of highly sensitive areas, and $87 \mathrm{~km}^{2}$ of extremely highly sensitive areas (Table 3). We conducted the Global Moran's I tests for spatial-autocorrelation on the sensitivity map using the spatial auto correlation tool in ArcGIS 10.2 software. The results indicate a high level of clustered distribution patterns of regional sensitivity (Moran Index $=0.51, \mathrm{Z}=13.87, \mathrm{P}=0.00$ ). The overall distribution trend indicates that the sensitivity of the inner side of Xiamen Bay was generally higher than that of the outer side. The sensitivity of the west side was greater than that of the east side. In particular, the areas in Jiulongjiang Estuary and along the Xiang'an-Dadeng coast had the highest sensitivity (Figure 8). Most areas of low sensitivity were located close to open water and had development activities of low intensity (e.g., Weitou Bay).

Table 3. Areas of five sensitivity levels in Xiamen Bay.

\begin{tabular}{cccc}
\hline Sensitivity Levels & Break Points & Area $\mathbf{( k m}^{\mathbf{2}}$ & Proportion \\
\hline Extremely high & $\geq 5.7$ & 87 & $7.5 \%$ \\
High & {$[4.8,5.7)$} & 235 & $20.3 \%$ \\
Medium & {$[4.3,4.8)$} & 395 & $34.1 \%$ \\
Low & {$[3.7,4.3)$} & 298 & $25.7 \%$ \\
Extremely low & $<3.7$ & 143 & $12.3 \%$ \\
\hline
\end{tabular}




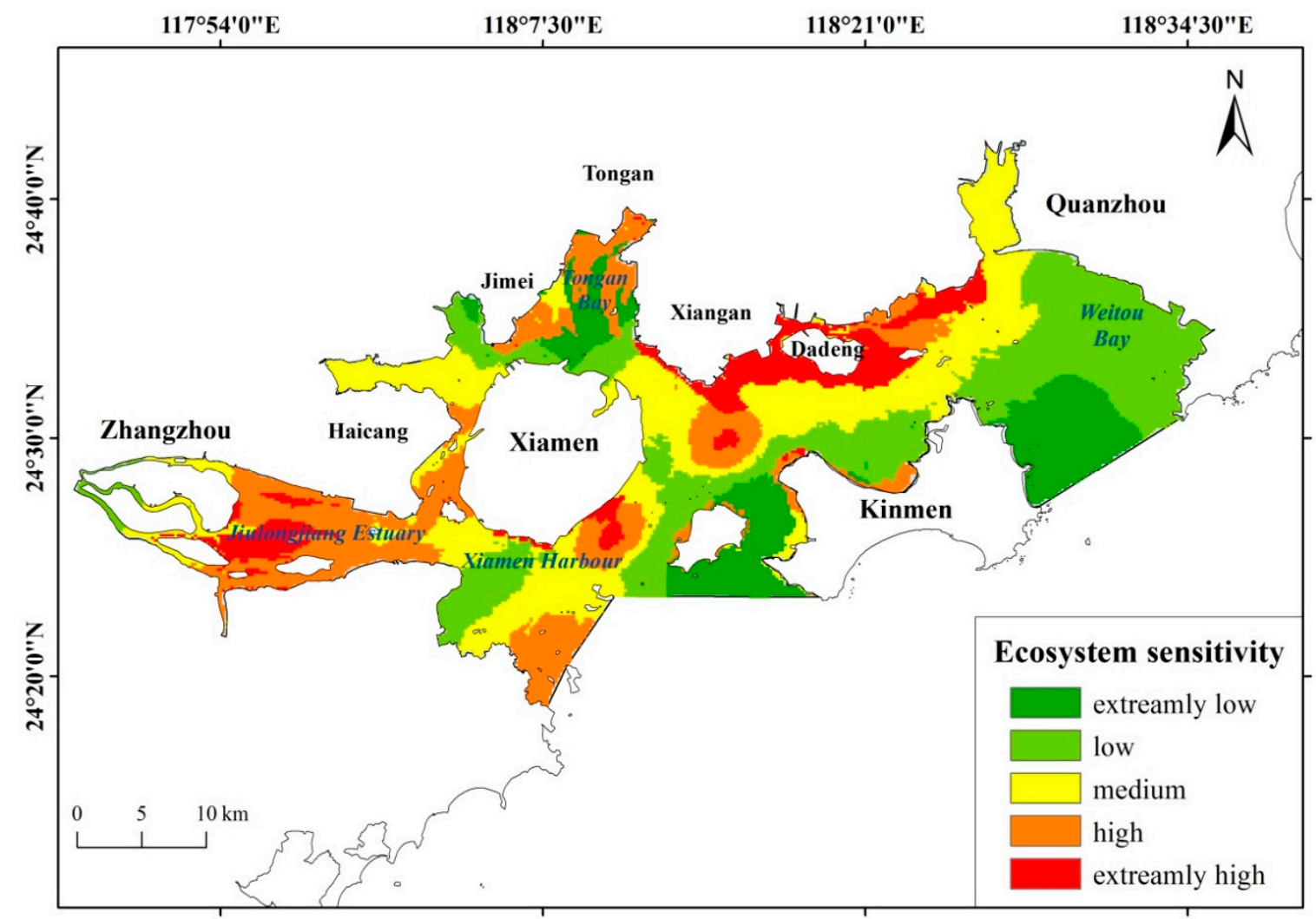

Figure 8. Results of the comprehensive evaluation of ecosystem sensitivity in Xiamen Bay, China.

In Xiamen Bay, areas with extremely high sensitivity had both high endogenous and exogenous sensitivity, indicating that these areas were of very high ecological significance and were susceptible to disturbance from environment change and human activities. Consequently, these areas represent an important focus for conservation and management. Highly sensitive areas might have less ecological significance; however, these areas are more likely to develop ecological and environmental problems or might have already suffered from habitat loss. Medium sensitivity suggests that the ecosystems of these areas have potential problems or are sensitive to certain pressures. Extremely-low and low sensitive areas represent areas where conditions are relatively stable, with the likelihood of problems occurring under disturbance being lower than that in other areas.

\section{Discussion}

\subsection{Comparison Analysis of Endogenous Sensitivity and Exogenous Sensitivity}

There was a significant difference in the spatial distribution of endogenous sensitivity and exogenous sensitivity in Xiamen Bay. Areas with high endogenous sensitivity were located in Jiulongjiang Estuary, the southeastern part of Xiamen Island, and along the Xiang'an coastline. Areas with high exogenous sensitivity were concentrated in Jiulongjiang Estuary and along the mainland coast. Compositional differences in sensitivity indicators led to this difference in the spatial distribution between the two types of sensitivity.

Differences between endogenous and exogenous sensitivity could help managers identify areas of high management interest. In Xiamen Bay, areas with high endogenous sensitivity did not show the same spatial distribution as did those with high exogenous sensitivity. This finding is of interest because areas with high endogenous sensitivity are often of a high conservation value, while areas with high exogenous sensitivity tend to have concentrated development activity. Therefore, the difference in the spatial distribution of these two types indicates that most development activities in Xiamen 
Bay have been restricted to areas away from areas of high protection value. Thus, the anthropogenic impacts to Xiamen Bay are successfully regulated by the long-standing ICM in an effective and scientific manner. Of note, areas with both high endogenous sensitivity and exogenous sensitivity were located in Jiulongjiang Estuary and along the coasts of Xiang'an and Dadeng Island, which indicates that these areas are development-protection conflict zones. This finding could be used to provide scientific basis for the selection of priority areas that need targeting in the next stage of the management actions (Figure 9).

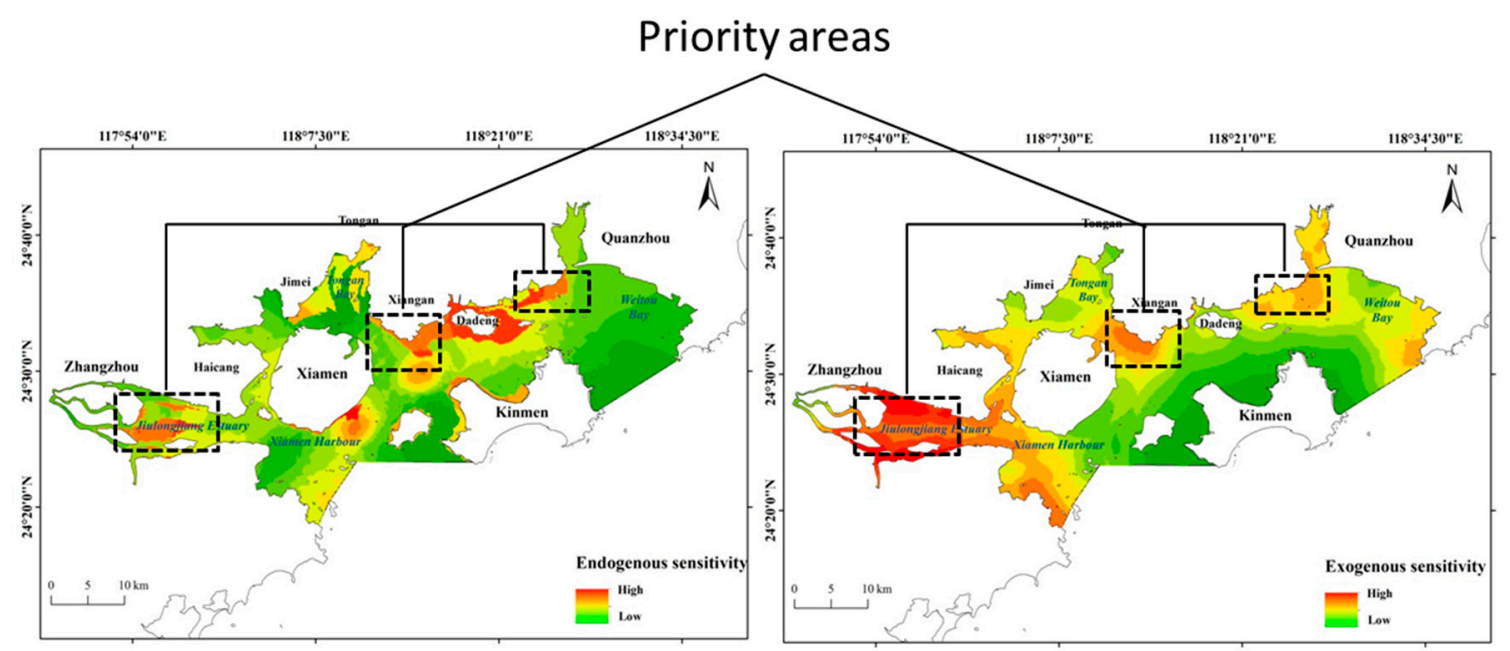

Figure 9. Priority areas for regulation and management.

\subsection{Strategy for Ecosystem-Based Management in Xiamen Bay}

Based on the results of the current study, the main external disturbances to Xiamen Bay were delineated. By sorting the weight contributions of exogenous sensitivity indicators (Figure 10), we found that the most influential pressures in the bay were pollution and reclamation. Thus, planned management actions should prioritize the comprehensive remediation of pollutants and the control of reclamation to reduce exogenous sensitivity and to improve the marine environment.

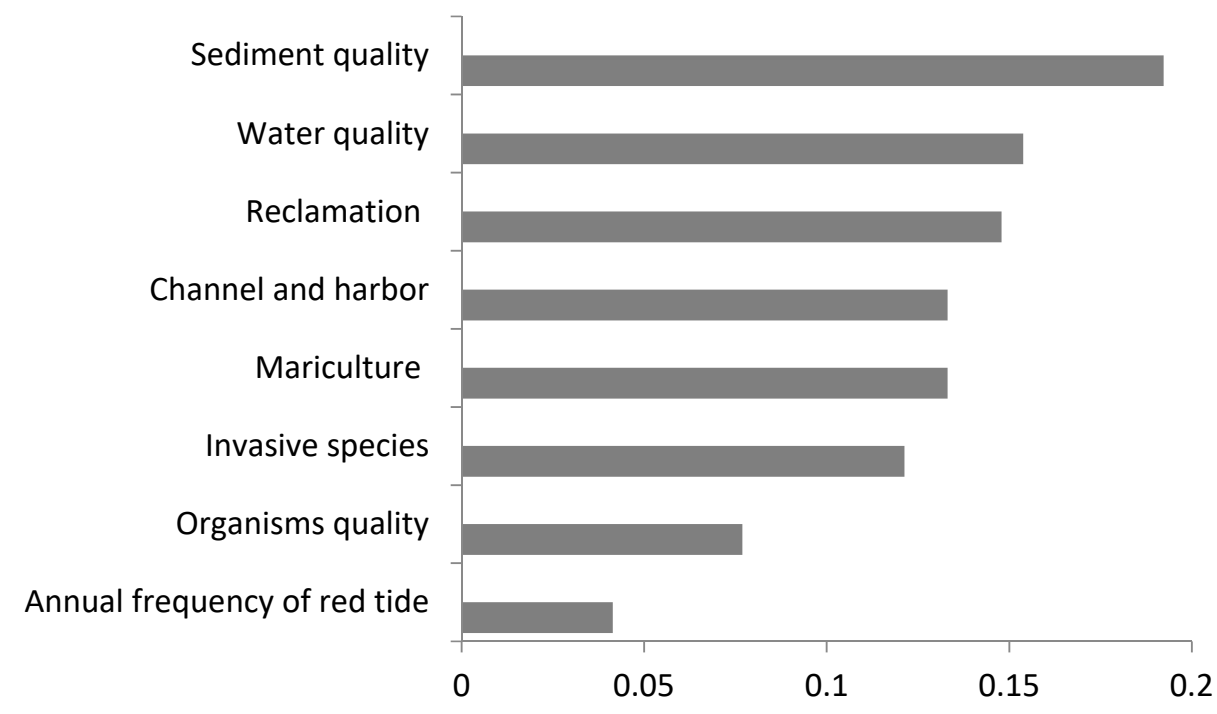

Figure 10. Contribution of exogenous sensitivity indicators. 
The ecological sensitivity in the study region was mapped based on the assessment. The results show that different management schemes could be proposed that are specific to the sensitivity of different areas (Figure 11).

1. Extremely high and highly sensitive areas in Xiamen Bay basically encompassed certain habitats, such as mangroves and sandy beaches, as well as habitats used by important species [55, 56]. A considerable portion of these areas already falls within protected areas, which should be under mandatory protection in accordance with the laws, regulations, and related plans. Development and construction activities that influence the ecological function of the region should be strictly prohibited, and exogenous sensitivity should be controlled or reduced as much as possible.

2. Medium-sensitivity areas in Xiamen Bay were mainly located in zones that supported harbors, shipping, mariculture, reclamation, and other coastal development, where sustainable sea-use management should be emphasized by controlling the scope and form of construction [57]. The introduction of development activities that adversely affect marine ecosystems should be limited and the methods of using natural resources should be improved. These areas could be treated as optimized development zones that are allowed to undergo a moderate degree of development under the "protection with development" policy.

3. Areas with extremely low and low sensitivity were mainly located in zones where protected species and typical habitats are absent and where marine development activities are weak. Therefore, the protection value of these areas is low and the ecological cost of development is also low. In MSP, these areas should be treated as priority zones for future construction and urbanization. Leisure and entertainment facilities should be promoted. However, all development should be subject to scientific regulation and control to ensure that human activities are gradually and properly transferred from the highly sensitive areas.

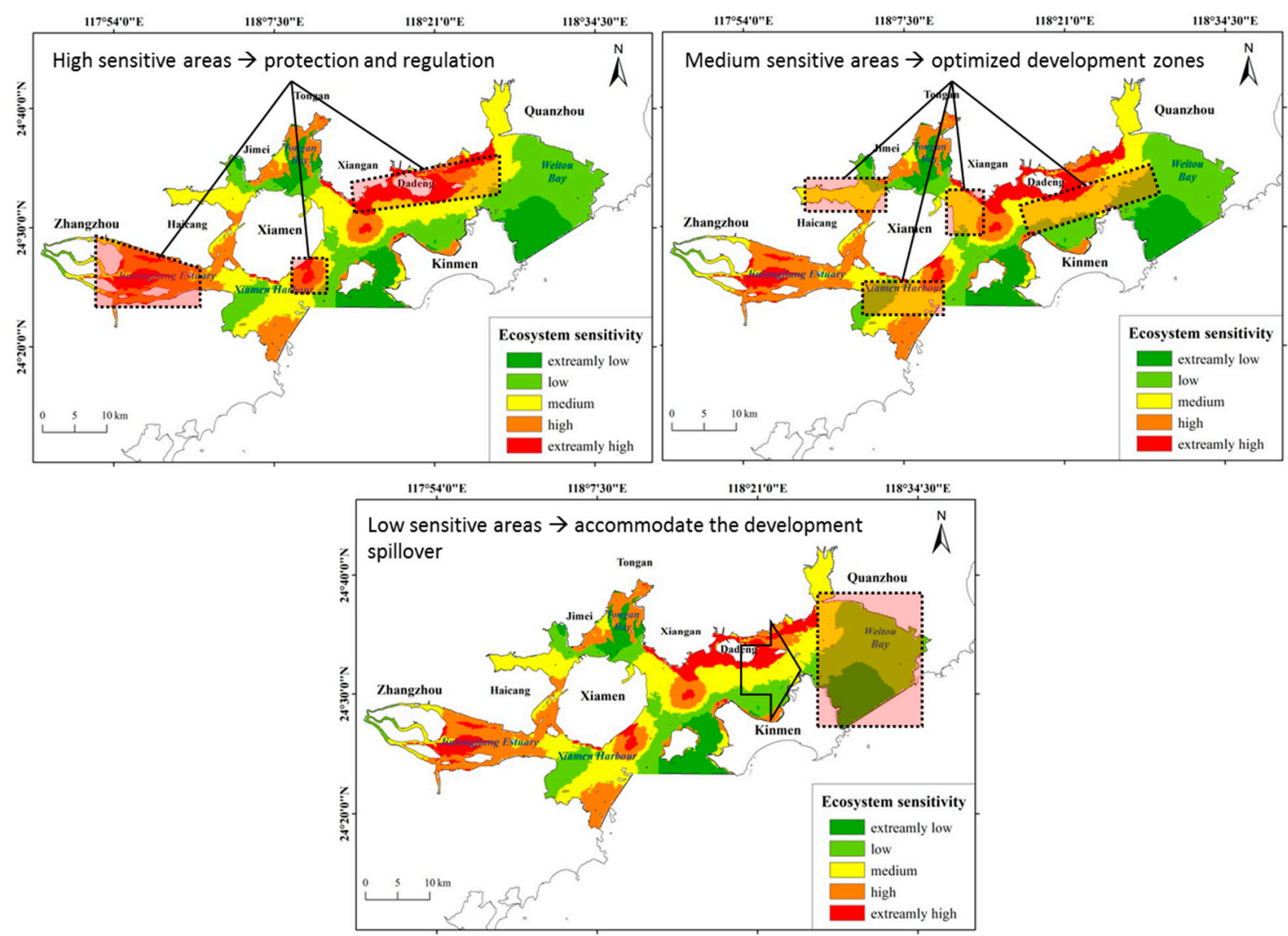

Figure 11. Strategies for ecosystem-based management in Xiamen Bay. 


\subsection{The Implementation in MSP}

The comprehensive assessment developed here effectively and flexibly utilized different types of data available in the study region. Monitoring data from local government, remote sensing data, and ecological survey data were used in this integrated framework. The indicators used in the evaluation could be altered to reflect the ecological characteristics of the region. Some indicators might only be appropriate for large scale regions, such as indicators about climate change, sea level rise, and storms, as the value of these indicators does not vary at small to medium scales. In addition, the weight of the indicators varies depending on the biogeographical characteristics of the study area. Therefore, as the scale and characteristics of the study area change, the evaluation indicators and their weights must be adjusted accordingly. For the general situation, we suggest that the indicators be selected from different factor levels to provide sufficient information. The data should also be obtained over a similar time scale to provide adequate information for MSP. On the other hand, as MSP areas usually have highly unique regional characteristics, local experts who are familiar with the study region should be invited to contribute to the weighting process to ensure that the weights reflect the actual situation.

As a tool to aid planning and the implementation of ecosystem-based MSP, this approach aimed to integrate spatial data on the distribution of marine habitats and multiple human activities. In the process of ecosystem-based MSP, this study provides important ecological information and supports policy makers by identifying and showing spatial information intuitively. Areas of high sensitivity suggest the need for protection and regulation, while areas with low sensitivity could accommodate spillover exploitation. We were also able to identify areas where conflict needs to be reduced between conservation and development by combining features of both endogenous sensitivity and exogenous sensitivity. Although multi-criteria analyses of marine ecological sensitivity exist [35-37], this study provided fine-scale analyses of ecological sensitivity, providing managers with more detailed and more targeted spatial information.

This study provides a good scientific basis for regional spatial planning decisions. In the Xiamen Bay MERL, most of the extremely highly sensitive areas and highly sensitive areas were included. Extremely highly sensitive areas were included in the first level control zones of MERL and highly sensitive areas were included in the second level control zones. Special control and regulating measures have been proposed for the different zones. For example, all new development activities will be prohibited in first level control zones. The scale and type of development activities will be strictly restricted in second level control zones. Ecological restoration will be carried out in these areas to reduce sensitivity. In the Jiulongjiang Estuary, an integrated ecological remediation action has been proposed, including the enhancement of sewage treatment, while marine aquaculture in and around the estuary wetland is planned to be removed [58]. In Tongan Bay, a dedicated area for the restoration of mangroves has been delimited [59]. These targeted actions will make important contributions to the sustainable development of the region.

\section{Conclusions}

Coastal marine ecosystems are sensitive to anthropogenic stressors and environmental change. However, in many cases, the lack of integrated, strategic, and comprehensive spatial planning often translates into a lack of conservation of ecologically sensitive marine areas [15]. The Chinese government proposed an ecosystem-based marine spatial planning scheme called "Marine Ecological Red Line", aimed at protecting ecologically sensitive areas. By integrating spatial data on marine habitats and human activities, complex ecological sensitivity assessments can provide highly effective support for MERL. This study proposed a comprehensive sensitivity assessment framework for a coastal marine ecosystem. The approach was developed to quantify and map marine ecological sensitivity by using a weighted summation model along with a GIS-based spatial analysis. Priority areas for conservation and regulation were identified according to the results, providing a scientific basis for marine spatial planning of MERL. 
Xiamen Bay was used as a case study for this approach. Under the proposed framework, comprehensive sensitivity values were calculated from 26 indicators. The results show the spatial distribution pattern of ecologically sensitive areas in the bay. The areas were separated into five levels of sensitivity. The extremely high and highly sensitive areas covered $87 \mathrm{~km}^{2}$ and $235 \mathrm{~km}^{2}$ areas, respectively. The ecological sensitivity of the inner side of the bay was generally higher than that of the outer side. The sensitivity of the west part of the bay was higher than that of the east part. The highest sensitivity was detected in areas near Jiulongjiang Estuary and along the coastline of Xiang'an. A comparison analysis between endogenous and exogenous sensitivity shows that conflicts were concentrated in Jiulongjiang Estuary. Regional ecologically sensitive features were used to propose ecosystem-based zoning and management strategies in the MERL.

This study developed an effective tool for ecosystem-based MSP. Although the evaluation framework of marine ecological sensitivity has wide applicability, the values of certain indicators did not change from small to medium scales and were not included in this case study because of research scale limitations; such indicators include climate change, sea level rise, and storms. Therefore, as the scale and characteristics of the study area change, the evaluation indicators within the framework should be flexibly selected. As the indicators change, the weighting should also be carefully adjusted according to regional characteristics. Furthermore, in addition to spatial analysis, temporal analysis represents an important direction of our future research. In this study, the evaluation was based on the current status; however, because the ICM is an adaptive management process, temporal dynamic assessments would provide enhanced support for management.

Author Contributions: Conceptualization: W.H., W.Y., B.C.; Methodology: W.H., B.C.; Investigation: Z.M., E.D., H.H., D.Z.; Data curation: E.D., H.H., D.Z.; Writing-Original Draft Preparation: W.H., W.Y., G.Y., Z.M.; Writing-Review and Editing: W.H., G.Y.; Supervision: B.C.; Funding acquisition: B.C., W.H., W.Y., G.Y.

Funding: This research was funded by the National Key Research and Development Program of China (2017YFC0506105), Public Science and Technology Research Funds Projects of Ocean (201405007), the National Natural Science Foundation of China (41906127) and the Science and technology project of Zhejiang Province (2017F30012).

Conflicts of Interest: The authors declare no conflict of interest.

\section{Appendix A}

Table A1. Weights of ecological sensitivity indicators.

\begin{tabular}{|c|c|c|c|c|}
\hline Target Level & Criterion Level & Factor Level & Indicator Level & Weight \\
\hline \multirow{10}{*}{$\begin{array}{c}\text { Ecosystem } \\
\text { sensitivity of } \\
\text { Xiamen Bay A1 }\end{array}$} & \multirow{10}{*}{$\begin{array}{l}\text { Endogenous } \\
\text { sensitivity } \\
\text { B1 }\end{array}$} & \multirow{5}{*}{$\begin{array}{l}\text { Distribution areas } \\
\text { of typical habitats } \\
\text { and important } \\
\text { species } C 1\end{array}$} & Mangrove D1 & 0.089 \\
\hline & & & $\begin{array}{l}\text { Waterfowl habitat } \\
\text { D2 }\end{array}$ & 0.089 \\
\hline & & & $\begin{array}{l}\text { Chinese White } \\
\text { Dolphin habitat D3 }\end{array}$ & 0.089 \\
\hline & & & $\begin{array}{c}\text { Amphioxus habitat } \\
\text { D4 }\end{array}$ & 0.089 \\
\hline & & & Sandy beach D5 & 0.089 \\
\hline & & \multirow{5}{*}{ Marine biome C2 } & $\begin{array}{c}\text { Chlorophyll } a \\
\text { content D6 }\end{array}$ & 0.021 \\
\hline & & & $\begin{array}{c}\text { Biodiversity index } \\
\text { of phytoplankton } \\
\text { D7 }\end{array}$ & 0.048 \\
\hline & & & $\begin{array}{l}\text { Biodiversity index } \\
\text { of zooplankton D8 }\end{array}$ & 0.036 \\
\hline & & & $\begin{array}{l}\text { Biodiversity index } \\
\text { of benthos D9 }\end{array}$ & 0.087 \\
\hline & & & $\begin{array}{l}\text { Biodiversity index } \\
\text { of nekton D10 }\end{array}$ & 0.030 \\
\hline
\end{tabular}


Table A1. Cont.

\begin{tabular}{|c|c|c|c|c|}
\hline Target Level & Criterion Level & Factor Level & Indicator Level & Weight \\
\hline & \multirow{13}{*}{$\begin{array}{l}\text { Exogenous } \\
\text { sensitivity } \\
\text { B2 }\end{array}$} & Hazard and risk C3 & $\begin{array}{l}\text { Annual frequency } \\
\text { of red tide D11 } \\
\text { Invasive species } \\
\text { D12 }\end{array}$ & 0.041 \\
\hline & & $\begin{array}{l}\text { Sea-use activities } \\
\text { C4 }\end{array}$ & $\begin{array}{c}\text { Mariculture D13 } \\
\text { Reclamation D14 } \\
\text { Channel and } \\
\text { harbor D15 }\end{array}$ & $\begin{array}{l}0.045 \\
0.050 \\
0.045\end{array}$ \\
\hline & & \multirow{11}{*}{$\begin{array}{c}\text { Environment } \\
\text { qualities C5 }\end{array}$} & $\begin{array}{l}\text { Petroleum in water } \\
\text { D16 }\end{array}$ & 0.013 \\
\hline & & & $\begin{array}{l}\text { Organic pollution } \\
\text { in water D17 }\end{array}$ & 0.013 \\
\hline & & & $\begin{array}{l}\text { Inorganic nitrogen } \\
\text { in water D18 }\end{array}$ & 0.013 \\
\hline & & & $\begin{array}{l}\text { Active phosphate } \\
\text { in water D19 }\end{array}$ & 0.013 \\
\hline & & & $\begin{array}{l}\text { Organic carbon in } \\
\text { sediment D20 }\end{array}$ & 0.013 \\
\hline & & & $\begin{array}{l}\text { Sulfides in } \\
\text { sediment D21 }\end{array}$ & 0.013 \\
\hline & & & $\begin{array}{l}\text { Polychlorinated } \\
\text { biphenyls in } \\
\text { sediment D22 }\end{array}$ & 0.013 \\
\hline & & & $\begin{array}{l}\text { Heavy metals in } \\
\text { sediment D23 }\end{array}$ & 0.013 \\
\hline & & & $\begin{array}{l}\text { Petroleum in } \\
\text { sediment D24 }\end{array}$ & 0.013 \\
\hline & & & $\begin{array}{l}\text { Heavy metals in } \\
\text { organisms D25 }\end{array}$ & 0.013 \\
\hline & & & $\begin{array}{l}\text { Petroleum in } \\
\text { organisms D26 }\end{array}$ & 0.013 \\
\hline
\end{tabular}

\section{References}

1. Ray, G.C.; Hayden, B.P. Coastal zone ecotones. In Landscape Boundaries; Springer: New York, NY, USA, 1992; pp. 403-420.

2. Reizopoulou, S.; Simboura, N.; Barbone, E.; Aleffi, F.; Basset, A.; Nicolaidou, A. Biodiversity in transitional waters: Steeper ecotone, lower diversity. Mar. Ecol. 2014, 35, 78-84. [CrossRef]

3. Halpern, B.S.; Walbridge, S.; Selkoe, K.A.; Kappel, C.V.; Micheli, F.; D’agrosa, C.; Bruno, J.F.; Casey, K.S.; Ebert, C.; Fox, H.E.; et al. A global map of human impact on marine ecosystems. Science 2008, 319, 948-952. [CrossRef] [PubMed]

4. Hoegh-Guldberg, O.; Bruno, J.F. The impact of climate change on the world's marine ecosystems. Science 2010, 328, 1523-1528. [CrossRef] [PubMed]

5. Perry, R.I.; Cury, P.; Brander, K.; Jennings, S.; Möllmann, C.; Planque, B. Sensitivity of marine systems to climate and fishing: Concepts, issues and management responses. J. Mar. Syst. 2010, 79, 427-435. [CrossRef]

6. Solan, M.; Cardinale, B.J.; Downing, A.L.; Engelhardt, K.A.; Ruesink, J.L.; Srivastava, D.S. Extinction and ecosystem function in the marine benthos. Science 2004, 306, 1177-1180. [CrossRef]

7. Worm, B.; Barbier, E.B.; Beaumont, N.; Duffy, J.E.; Folke, C.; Halpern, B.S.; Jackson, J.C.; Lotze, H.K.; Micheli, F.; Palumbi, S.R.; et al. Impacts of biodiversity loss on ocean ecosystem services. Science 2006, 314, 787-790. [CrossRef]

8. Deegan, L.A.; Johnson, D.S.; Warren, R.S.; Peterson, B.J.; Fleeger, J.W.; Fagherazzi, S.; Wollheim, W.M. Coastal eutrophication as a driver of salt marsh loss. Nature 2012, 490, 388. [CrossRef]

9. Johnston, E.L.; Mayer-Pinto, M.; Crowe, T.P. Chemical contaminant effects on marine ecosystem functioning. J. Appl. Ecol. 2015, 52, 140-149. [CrossRef] 
10. Hewitt, J.E.; Ellis, J.I.; Thrush, S.F. Multiple stressors, nonlinear effects and the implications of climate change impacts on marine coastal ecosystems. Glob. Chang. Biol. 2016, 22, 2665-2675. [CrossRef]

11. Le Moal, M.; Gascuel-Odoux, C.; Ménesguen, A.; Souchon, Y.; étrillard, C.; Levain, A.; Moatar, F.; Pannard, A.; Souchu, P.; Lefebvre, A.; et al. Eutrophication: A new wine in an old bottle? Sci. Total Environ. 2019, 651, 1-11. [CrossRef]

12. Douvere, F.; Ehler, C. Ecosystem-based marine spatial management: An evolving paradigm for the management of coastal and marine places. Ocean Yearb. Online 2009, 23, 1-26. [CrossRef]

13. Zeng, J.N.; Chen, Q.Z.; Huang, W.; Du, P.; Yang, H. Transformation and Development of China's Marine Ecological Protection System-From Marine Protected Areas to Marine Ecological Red Line Areas. Acta Ecol. Sin. 2016, 36, 1-10. (In Chinese)

14. Lu, W.H.; Liu, J.; Xiang, X.Q.; Song, W.L.; Mcllgorm, A.A. Comparison of marine spatial planning approaches in China: Marine functional zoning and the marine ecological red line. Mar. Policy 2015, 62, 94-101. [CrossRef]

15. Zhao, P.; Lu, W.; Song, J.; Stuart, P.; Yang, H. Natural coast protection and use in China: Implications of resource protection "Redline" policies. Coast. Manag. 2016, 44, 21-35.

16. Wang, C.S.; Sun, G.Y.; Dang, L.J. Identifying ecological red lines: A case study of the coast in Liaoning province. Sustainability 2015, 7, 9461-9477. [CrossRef]

17. Shi, Y.S.; Li, J.Q.; Xie, M.Q. Evaluation of the ecological sensitivity and security of tidal flats in Shanghai. Ecol. Indic. 2018, 85, 729-741. [CrossRef]

18. Zheng, Y.; Lan, S.R.; Chen, W.Y.; Chen, X.Y.; Xu, X.X.; Chen, Y.N.; Dong, J.W. Visual sensitivity versus ecological sensitivity: An application of GIS in urban forest park planning. Urban For. Urban Greeen. 2019, 41, 139-149. [CrossRef]

19. Crowder, L.; Norse, E. Essential ecological insights for marine ecosystem-based management and marine spatial planning. Mar. Policy 2008, 32, 772-778. [CrossRef]

20. Douvere, F. The importance of marine spatial planning in advancing ecosystem-based sea use management. Mar. Policy 2008, 32, 762-771. [CrossRef]

21. Dunstan, P.K.; Bax, N.J.; Dambacher, J.M.; Hayes, K.R.; Hedge, P.T.; Smith, D.C.; Smith, A.D. Using ecologically or biologically significant marine areas (EBSAs) to implement marine spatial planning. Ocean Coast. Manag. 2016, 121, 116-127. [CrossRef]

22. Cosme, N.; Hauschild, M.Z. Effect factors for marine eutrophication in LCIA based on species sensitivity to hypoxia. Ecol. Indic. 2016, 69, 453-462. [CrossRef]

23. Trannum, H.C.; Gundersen, H.; Oug, E.; Rygg, B.; Norderhaug, K.M. Soft bottom benthos and responses to climate variation and eutrophication in Skagerrak. J. Sea Res. 2018, 141, 83-98. [CrossRef]

24. Halouani, G.; Le Loc'h, F.; Shin, Y.J.; Velez, L.; Hattab, T.; Romdhane, M.S.; Lasram, F.B.R. An end-to-end model to evaluate the sensitivity of ecosystem indicators to track fishing impacts. Ecol. Indic. 2019, 98, 121-130. [CrossRef]

25. Cheung, W.W.; Oyinlola, M.A. Vulnerability of flatfish and their fisheries to climate change. J. Sea Res. 2018, 140, 1-10. [CrossRef]

26. Roué-Legall, A.; Lucotte, M.; Carreau, J.; Canuel, R.; Garcia, E. Development of an ecosystem sensitivity model regarding mercury levels in fish using a preference modeling methodology: Application to the Canadian boreal system. Environ. Sci. Technol. 2005, 39, 9412-9423. [CrossRef] [PubMed]

27. Lathrop, R.G.; Bognar, J.; Buenaventura, E.; Ciappi, M.; Green, E.; Belton, T.J. Establishment of Marine Protected Areas to Reduce Watercraft Impacts in Barnegat Bay, New Jersey. J. Coast. Res. 2017, 78, 277-286. [CrossRef]

28. García-Ayllón, S. GIS assessment of mass tourism anthropization in sensitive coastal environments: Application to a case study in the mar menor area. Sustainability 2018, 10, 1344. [CrossRef]

29. Ostrom, E. A general framework for analyzing sustainability of social-ecological systems. Science 2009, 325, 419-422. [CrossRef]

30. Borja, A.; Galparsoro, I.; Solaun, O.; Muxika, I.; Tello, E.M.; Uriarte, A.; Valencia, V. The European Water Framework Directive and the DPSIR, a methodological approach to assess the risk of failing to achieve good ecological status. Estuar. Coast. Shelf Sci. 2006, 66, 84-96. [CrossRef]

31. Levin, P.S.; Fogarty, M.J.; Murawski, S.A.; Fluharty, D. Integrated ecosystem assessments: Developing the scientific basis for ecosystem-based management of the ocean. PLoS Biol. 2009, 7, e1000014. [CrossRef] 
32. Atkins, J.P.; Burdon, D.; Elliott, M.; Gregory, A.J. Management of the marine environment: Integrating ecosystem services and societal benefits with the DPSIR framework in a systems approach. Mar. Pollut. Bull. 2011, 62, 215-226. [CrossRef] [PubMed]

33. Kelble, C.R.; Loomis, D.K.; Lovelace, S.; Nuttle, W.K.; Ortner, P.B.; Fletcher, P.; Cook, G.S.; Lorenz, J.J.; Boyer, J.N. The EBM-DPSER conceptual model: Integrating ecosystem services into the DPSIR framework. PLOS ONE 2013, 8, e70766. [CrossRef] [PubMed]

34. Chi, Y.; Zhang, Z.W.; Gao, J.H.; Xie, Z.L.; Zhao, M.W.; Wang, E.K. Evaluating landscape ecological sensitivity of an estuarine island based on landscape pattern across temporal and spatial scales. Ecol. Indic. 2019, 101, 221-237. [CrossRef]

35. Wang, C.Y.; Pan, D.L. Zoning of Hangzhou Bay ecological red line using GIS-based multi-criteria decision analysis. Ocean Coast. Manag. 2017, 139, 42-50.

36. Wood, L.J.; Dragicevic, S. GIS-based multicriteria evaluation and fuzzy sets to identify priority sites for marine protection. Biodivers. Conserv. 2007, 16, 2539-2558. [CrossRef]

37. Qiu, P.; Xu, S.; Xie, G.; Tang, B.; Bi, H.; Yu, L. Analysis of the ecological vulnerability of the western Hainan Island based on its landscape pattern and ecosystem sensitivity. Acta Ecol. Sin. 2007, 27, 1257-1264.

38. Muñoz, M.; Reul, A.; de Sola, L.G.; Lauerburg, R.A.M.; Tello, O.; Gimpel, A.; Stelzenmüller, V. A spatial risk approach towards integrated marine spatial planning: A case study on European hake nursery areas in the North Alboran Sea. Mar. Environ. Res. 2018, 142, 190-207. [CrossRef]

39. Ortiz, G.; Dominguez-Gómez, J.A.; Tur, A.; Maria Urgeghe, A. Participatory multi-criteria decision analysis for prioritizing impacts in environmental and social impact assessments. Sustain. Sci. Pract. Policy 2018, 14, 6-21. [CrossRef]

40. Manea, E.; Di Carlo, D.; Depellegrin, D.; Agardy, T.; Gissi, E. Multidimensional assessment of supporting ecosystem services for marine spatial planning of the Adriatic Sea. Ecol. Indic. 2019, 101, 821-837. [CrossRef]

41. Kirkman, S.P.; Holness, S.; Harris, L.R.; Sink, K.J.; Lombard, A.T.; Kainge, P.; Majiedt, P.; Nsiangango, S.E.; Nsingi, K.K.; Samaai, T. Using Systematic Conservation Planning to support Marine Spatial Planning and achieve marine protection targets in the transboundary Benguela Ecosystem. Ocean Coast. Manag. 2019, 168, 117-129. [CrossRef]

42. Hiddink, J.G.; Jennings, S.; Kaiser, M.J. Assessing and predicting the relative ecological impacts of disturbance on habitats with different sensitivities. J. Appl. Ecol. 2007, 44, 405-413. [CrossRef]

43. Zhang, Z.H.; Xu, J.H.; Han, G.F. Ecological sensitive area division indicator system. Ecol. Sci. 2007, 1, 17. (In Chinese)

44. Gorman, D.; Corte, G.; Checon, H.H.; Amaral, A.C.Z.; Turra, A. Optimizing coastal and marine spatial planning through the use of high-resolution benthic sensitivity models. Ecol. Indic. 2017, 82, 23-31. [CrossRef]

45. Conti, L.A.; Fonseca Filho, H.; Turra, A.; Amaral, A.C.Z. Building a local spatial data infrastructure (SDI) to collect, manage and deliver coastal information. Ocean Coast. Manag. 2018, 164, 136-146. [CrossRef]

46. Wang, X.; Wu, F.; Turvey, S.T.; Rosso, M.; Tao, C.; Ding, X.; Zhu, Q. Social organization and distribution patterns inform conservation management of a threatened Indo-Pacific humpback dolphin population. J. Mammal. 2015, 96, 964-971. [CrossRef]

47. Yu, Z.; Yu, J. Study on value assessment of rare and endangered species in marine reserve: A case of the Xiamen rare marine species national nature reserve. Chin. J. Mar. Environ. Sci. 2017, 36, 81-86. (In Chinese)

48. Zhang, X.; Xue, X. Analysis of marine environmental problems in a rapidly urbanising coastal area using the DPSIR framework: A case study in Xiamen, China. J. Environ. Plan. Manag. 2013, 56, 720-742. (In Chinese) [CrossRef]

49. Fang, Q.; Ma, D.; Zhang, L.; Zhu, S. Marine functional zoning: A practical approach for integrated coastal management (ICM) in Xiamen. Ocean Coast. Manag. 2018, in press. [CrossRef]

50. Su, J.; Peng, B. Evaluating the trade-offs between alternative coastal policies: Evidence from Xiamen's ICM programme. Ocean Coast. Manag. 2018, in press. [CrossRef]

51. Saaty, T.L. How to make a decision: The analytic hierarchy process. Eur. J. Oper. Res. 1990, 48, 9-26. [CrossRef]

52. Tran, L.T.; Knight, C.G.; O’Neill, R.V.; Smith, E.R.; Riitters, K.H.; Wickham, J. Fuzzy decision analysis for integrated environmental vulnerability assessment of the Mid-Atlantic region. Environ. Manag. 2002, 29, 845-859. [CrossRef] 
53. Scolozzi, R.; Morri, E.; Santolini, R. Delphi-based change assessment in ecosystem service values to support strategic spatial planning in Italian landscapes. Ecol. Indic. 2012, 21, 134-144. [CrossRef]

54. Dang, G.F.; Ji, S.Z. Ecological Sensitivity Evaluation Based on GIS in Qinba Mountainous Area-A Case Study of Longnan Mountainous Area. Chin. Agric. Sci. Bull. 2017, 33, 118-127.

55. Fang, S.H.; Lu, X.M. Resources and Protetion of Amphioxus (Branchiostoma belcheri) in Xiamen National Natural Reserve Area of Rare Marine Species. Mar. Sci. 2002, 26, 12. (In Chinese)

56. Lin, P.; Zhang, Y.H.; Yang, Z.W. Protection and restoration of mangroves along the coast of Xiamen. J. Xiamen Univ. (Nat. Sci.) 2005, 44, 1-6. (In Chinese)

57. Lin, T. Study on Coastal Ecological Safety Assessment Mode and Case Studies. Ph.D. Thesis, Xiamen University, Xiamen, China, 2007. (In Chinese).

58. JiulongJiang Estuary and Xiamen Bay Ecological Integrated Governance Action Plan; Fujian Provincial Department of Environment and Ecology: Fuzhou, Fujian, January 2019. (In Chinese)

59. Guo, Q. XiaTanwei in Tong'an Bay will become the largest mangrove area in Xiamen. Xiamen Net News, March 2018. (In Chinese)

(C) 2019 by the authors. Licensee MDPI, Basel, Switzerland. This article is an open access article distributed under the terms and conditions of the Creative Commons Attribution (CC BY) license (http://creativecommons.org/licenses/by/4.0/). 